\title{
Política e território: a invenção de uma região metropolitana
}

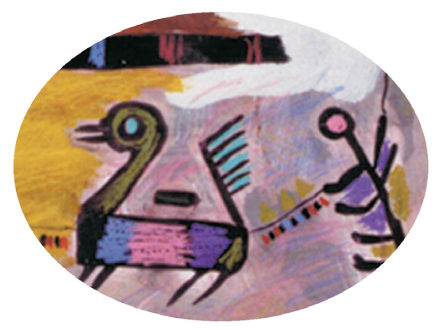

Ricardo José Batista Nogueira*

\section{Resumo}

Este trabalho mostra a capacidade que a ação política tem de fazer a geografia, ou seja, criar territórios necessários para o exercício da gestão estatal. Aponta-se a criação da Região Metropolitana de Manaus como uma invenção geográfica inusitada da política local e como esses novos territórios têm servido a diversos Estados como meio imprescindível dos governadores de Estados terem uma intervenção política nas aglomerações urbanas.

Palavras-chave: Geografia Política; Região Metropolitana; Urbanização; Manaus.

\begin{abstract}
The main aim of this article is to show the capacity that political action has to create geography, which means, create territories that are need for government administration. The creation of the Metropolitan Region of Manaus is seemed as a geographical invention from the local politics. Not only there but in many order States the adoption of this political system has become an alternative, not just in order to acquired financial recourses, but also as a strong way of gain political power by interviewing on the police of urban agglomeration.
\end{abstract}

Keywords: Political Geography; Metropolitan Regions; Urbanization; Manaus.

\footnotetext{
* Doutor em Geografia (Geografia Humana) pela Universidade de São Paulo (2002). É professor associado I da Universidade Federal do Amazonas.
} 


\section{Introdução}

O vínculo entre o espaço e a política já foi amplamente debatido entre os mais diversos autores em diferentes perspectivas, ficando evidente para a maioria deles que o espaço será aquilo que os agentes sociais definirem a partir dos embates travados politicamente. Para compreender o processo de criação da mais nova região metropolitana no Brasil, recuperaremos, de modo breve, alguns postulados teóricos sobre a relação espaço e poder político; o recente processo de urbanização brasileira, que modifica politicamente o espaço urbano; a história da instituição das regiões metropolitanas no Brasil em pleno regime militar; e como se deu localmente a instituição artificial da Região Metropolitana de Manaus, pela Lei Complementar n.. 52/2007, de 30/5/2007, da Assembleia Legislativa do Estado do Amazonas, composta por sete municípios.

\section{Sobre Espaço, Poder e Recortes Territoriais}

O fenômeno da urbanização interpretado basicamente a partir da economia política ressaltou os aspectos da aglomeração de população e sua consequente divisão social do trabalho levada ao extremo na mesma proporção da expansão urbana. A constituição de mercados os mais diversos, a começar pelo mercado de terras, deu margem à criação daquilo que os economistas chamam de economia de aglomeração, que, tendo um limite, estender-se-á até o momento em que essa aglomeração passe a gerar as chamadas deseconomias de aglomeração, decorrente de congestionamentos, elevação dos custos próprios à aglomeração etc.

Essa base reflexiva sobre as aglomerações urbanas, que remete aos processos de valorização do espaço, em que indivíduos, grupos e empresas buscam instalarem-se em lugares que possam lhes ser mais rentáveis, está plenamente consolidada e tem contribuído para o entendimento das mais diversas cidades no mundo. Harvey (1982), por exemplo, ao tentar exemplificar o processo de ocupação de uma cidade, usa como metáfora a ocupação de um teatro, onde aqueles que chegam primeiro vão procurar sentar nos melhores lugares para ver o espetáculo. Poderíamos afirmar que a ocupação dos melhores lugares é diretamente proporcional à capacidade de pagamento por eles, seja 
num estádio, num teatro ou na cidade.

Numa abordagem que prioriza a política, Lefebvre (1976: 31), procurando esclarecer o que seria o espaço, aponta três hipóteses sobre ele, onde a primeira refere-se ao espaço em forma pura, em essência, própria da filosofia cartesiana; a segunda diz respeito ao espaço como um produto da sociedade, resultado da história, de um passado, dando como exemplo as atividades agrícolas, industriais etc., sendo, portanto, um espaço objetivo, ou melhor, diz ele, objetivação do social. Enfim, é na terceira hipótese que ele aponta para o caráter do espaço como um instrumento, um meio e uma mediação. Assim, o espaço é um instrumento político intencionalmente manipulado. Nessa hipótese a própria representação do espaço estaria, segundo ele, a serviço de uma estratégia, sendo ao mesmo tempo abstrata e concreta, pensada e projetada.

Como o objetivo claramente definido aqui é pensar o espaço urbano como um espaço com um enorme potencial político, que pode se originar dos diversos agentes sociais, encontramos em Raffestin (1996) algumas referências que reforçam o que pretendemos apresentar adiante sobre a artificialidade da Região Metropolitana de Manaus.

Quando trata das quadrículas do poder, Raffestin recupera a noção de limite para expor as suas considerações sobre como o poder rege o espaço à sua vontade. Aponta primeiramente que o limite, visível ou não, é um sinal, ou seja, uma informação utilizada pelas coletividades para marcar o território, estruturando-o. Assim, todo limite seria uma representação do poder, recortando, delimitando e demarcando as ações do poder instituído. Em segundo lugar, é justamente em razão da demarcação que o exercício das funções legais e das normas das instituições jurídicas se concretiza. Portanto,

o exercício do poder implica a manipulação constante da oposição continuidade versus descontinuidade. $\mathrm{O}$ jogo estrutural do poder conduz a assegurar ora a continuidade, deslocando os limites, ora a provocar a descontinuidade, criando novos limites (p. 169).

Embora estejamos muito mais habituados a identificar esses processos, ocorrendo na escala dos Estados nacionais, quando sua divisão interna é 
decorrente, em primeiro lugar, da forma de Estado - unitário ou federado que se tem, e, em segundo lugar, da própria relação entre Estado, sociedade e movimentos regionais, o espaço urbano, pela sua característica de aglomeração de sujeitos sociais, exige também dos seus governos toda uma arquitetura de divisão do território para ter o controle do urbano. Claval (1979) fala em geometrias quando procura explicitar as formas de controle do espaço pelo poder. Para ele, a administração burocrática do espaço pelo Estado ocorre a partir das divisões instituídas, e, em geral, essas divisões são criticadas pelos geógrafos porque elas não possuem um critério científico como uma área homogênea, uma bacia polarizada ou mesmo a natureza das atividades econômicas, sendo, portanto, irracional. No entanto, Claval adverte que a finalidade das delimitações não é científica, mas é realizada para permitir o controle das pessoas. Isso pode nos remeter, por exemplo, às circunscrições que existem no espaço urbano como as zonas, os bairros, os setores censitários do IBGE, as zonas eleitorais, os Códigos de Endereçamento Postais, as áreas de abrangências dos distritos policiais, dos postos de saúde e tantas outras que ora identificamos, ora sequer sabemos de sua existência. Ou seja, o desenho, a representação cartográfica do espaço, o recorte criado não apresenta nenhum caráter de ingenuidade.

Esses procedimentos técnicos, mas essencialmente políticos, não são recentes, remontam evidentemente às relações de poder e de como o espaço é instrumento e instrumentalizado para isso. Brito (1986) afirma que essa técnica já era conhecida dos gregos, quando nos tempos de Clístenes, este dividiu a Ática em três distritos - Cidade, Costa e Interior - para impedir a reconstituição das representações regionais, sendo, ainda, cada um dos distritos subdivididos em outras dez circunscrições territoriais. Noutro exemplo, mostra como o governador Gerry, do Estado de Massachusetts, em 1812, criou uma nova circunscrição eleitoral para pôr o seu partido em vantagem, cuja representação cartográfica assemelhou-se a uma salamandra (salamander), ficando essa técnica de recortar as circunscrições eleitorais em função dos interesses circunstanciais de um homem ou de um partido conhecida como gerrymander.

\section{Da Metrópole à Região Metropolitana}

A urbanização da sociedade, ainda um processo em curso em diversos 
países, tem conduzido a uma verdadeira mudança na organização do espaço em função das exigências que a aglomeração de pessoas numa cidade impõe. Necessidades das mais variadas ordens devem ser satisfeitas e realizadas principalmente pelo Estado, pois é ele quem termina tendo os mecanismos de controle do espaço público. Organizar e regulamentar a circulação, o abastecimento, o uso do solo, distribuição dos equipamentos públicos e outras necessidades comuns forçam a instituição de um aparato estatal voltado exclusivamente para isso.

As grandes aglomerações urbanas, pela capacidade que possuem de catalisar fluxos em torno de si, constituem-se desse modo num ponto prioritário da ação estatal. Os clássicos estudos sobre as funções urbanas, a constituição de hierarquia e das redes demonstram que as maiores cidades constroem em torno de si regiões que encerram dependências de atividades e serviços. Se no passado a cidade era a expressão de uma região, hoje se afirma que as grandes cidades fazem as regiões na medida em que comandam o que a região deve fazer. Teoricamente, o predomínio é de uma abordagem da economia urbana, ficando a política urbana entendida como ações que o Estado deve realizar na cidade para amenizar os diversos conflitos de interesses dos seus habitantes.

No Brasil, o processo de urbanização é um fenômeno recente, pois, em primeiro lugar, o percentual de população residindo nas cidades só ultrapassa a população rural no censo de 1970; e, em segundo lugar, a formação das grandes cidades, com mais de um milhão de habitantes, só se dispersa do eixo São Paulo-Rio de Janeiro também em 1970, quando Belo Horizonte e Recife são consideradas cidades milionárias (SANTOS, 1994). Mas as cidades com mais de quinhentos mil habitantes também se pulverizam pelo território mostrando a intensidade do processo de urbanização. No Norte do Brasil, Belém atinge essa marca já no censo de 1970, enquanto Manaus terá de aguardar a virada da década (1980) para atingir a mesma marca. No censo de 1990, porém, ultrapassa um milhão de habitantes.

Não é demais lembrar que a intensidade no crescimento das cidades no Norte do Brasil foi decorrência do grande estímulo dado à migração e a colonização pelo governo federal para a região. Associado a isso, o próprio crescimento vegetativo, estando acima da média nacional, reforçado pelas migrações intrarregionais, fizeram com que as principais cidades, as capitais, atingissem contingentes urbanos significativos do total do Estado federado. 
Santos e Silveira (2001), na análise que fazem da urbanização do território brasileiro, destacam que esse fenômeno desde a década de 1950 passou pelos seguintes processos: primeiro, uma urbanização aglomerada com o crescimento do número de cidade com mais de 20 mil habitantes; seguido por uma urbanização concentrada, com a ampliação dos núcleos intermediários; sendo concluído com o estágio da metropolização, onde se ampliou consideravelmente o número de cidades com mais de quinhentos mil habitantes e as milionárias. Assim, "As regiões metropolitanas, onde se diversifica e avoluma a divisão do trabalho, conhecem uma aceleração e aprofundamento de uma série de processos econômicos e sociais” (p. 203).

Essa avaliação contempla plenamente o recente fenômeno urbano brasileiro, gerador das grandes aglomerações como lugar de vida da maioria dos brasileiros, pois aí estão localizados os bens e principalmente os serviços necessários à reprodução das mais diversas atividades sociais.

Foi justamente esse fato, porém, de aglomerar um contingente populacional substancial, comandado basicamente pelas "cidades capitais" que, gradativamente, incorporou o seu entorno constituído de outras cidades, constituindo uma conurbação, que, em 1973, o governo federal, elaborando um recorte territorial completamente novo no território brasileiro, criou as regiões metropolitanas, apesar da "existência de experiências embrionárias de administrações metropolitanas", em São Paulo e Salvador, conforme aponta Rolnik e Someck (2003).

Subvertendo a noção clássica de região, predominante e difundida pela Geografia como um espaço com características naturais comuns, bem como escapando à regionalização político-administrativa existente (Norte, Nordeste, Sul, Sudeste e Centro-Oeste), o governo federal, durante o regime militar, instituiu uma regionalização capaz de controlar as ações da oposição localizada nas grandes aglomerações. Tendo suprimido as eleições para os governos estaduais em 1967, quando estes passaram a ser indicados pelo poder central, em 1973 cria regiões metropolitanas naquelas cidades de maior contingente populacional com o objetivo de dar mais poder aos governadores nas áreas mais populosas, visto que uma série de atribuições para essa região urbanizada ficaria sob o domínio do governador de Estado, como, por exemplo, a própria indicação da composição do Conselho Deliberativo, órgão principal de gestão da região metropolitana. Essa é, portanto, uma entidade territorial 
exclusivamente administrativa, não comportando, portanto, representação política parlamentar, como Estados e municípios.

Isso só corrobora que o ato de regionalizar possui um componente político preponderante, reclamado por Lacoste (1974), quando critica o tradicional conceito de região como natural, e no Brasil por algumas obras, como Oliveira (1977) e Corrêa (1990). Mais recentemente, Ribeiro (2004: 214) aprofunda a questão desse ato de regionalizar apresentando-lhe como fato e como ferramenta. Como fato, a regionalização "encontra-se vinculada aos jogos dinâmicos da disputa de poder, inscritos nas diferentes formas de apropriação do território", sendo variável fundamental a periodização; e, como ferramenta, a regionalização, marcada pelo planejamento conduzido pelo Estado, expressase "pela imposição do agir instrumental e estratégico", sendo utilizada pelos agentes econômicos hegemônicos, desestabilizando a estrutura espacial do país. Por isso mesmo que a regionalização como ferramenta é hoje disputada por diversos agentes sociais: Estado, corporações, movimentos sociais etc.

Pode-se, assim, perceber que a criação de uma região metropolitana resulta de um fato - disputas políticas que se manifestam territorialmente - e se constitui como ferramenta - o recorte instituído permite, legaliza e autoriza as ações. O que caracteriza uma região metropolitana é, essencialmente, o fato de duas ou mais cidades pertencentes a unidades políticas municipais diferentes compartilharem uma área urbana integrada econômica, social e geograficamente, pois isso exige que ambas passem a discutir sua organização espacial, o zoneamento e seus fluxos, o uso dos recursos naturais, a complexidade das funções desempenhadas etc.

As regiões metropolitanas criadas em 1973 - São Paulo, Rio de Janeiro, Belo Horizonte, Porto Alegre, Curitiba, Salvador, Recife, Fortaleza e Belém eram justamente as cidades mais populosas do Brasil, apresentavam as características acima, além de reunir o maior contingente de eleitores e foram palco das grandes manifestações de oposição ao regime militar. Daí sua institucionalização.

A Lei Complementar n. ${ }^{\circ}$ 14, de 8 de junho de 1973, que criou as regiões metropolitanas, estabelecia, em seu artigo $5^{\circ}$, a necessidade da unificação da execução dos serviços comuns aos municípios componentes a serem realizados quer pela concessão a entidade estadual, quer pela constituição de empresa de âmbito metropolitano, ou ainda outros processos, convênios que pudessem ser 
efetivados. O elenco dos serviços comuns foi definido como: o planejamento integrado do desenvolvimento econômico e social; saneamento básico abastecimento de água, rede de esgoto e serviço de limpeza pública; uso do solo metropolitano; transporte e sistema viário; produção e distribuição de gás combustível canalizado; e aproveitamento dos recursos hídricos e controle da poluição ambiental.

O artigo 6. ${ }^{\circ}$ é aquele que claramente indica a prioridade dos municípios que compõem a região metropolitana na obtenção dos recursos federais e estaduais, bem como financiamento e garantia de empréstimos. Ou seja, além do controle político sobre a região, a oferta preferencial de recursos financeiros assegurava a relação de dependência. Sob um regime autoritário isso é de fácil compreensão em função da centralização excessiva. O processo de redemocratização do país, porém, iniciado a partir de 1984, e culminando com a elaboração da Constituição de 1988, democrática e descentralizadora, não só manteve a existência desse recorte territorial urbano (um entulho autoritário?) como passou a competência para os Estados federados criarem as suas regiões metropolitanas.

Até então as regiões metropolitanas eram aquelas criadas pelo governo federal durante o regime militar. Após a Constituição surgiram nada menos que 17 novas regiões metropolitanas por decisão das Assembleias Estaduais, algumas inclusive fora das capitais estaduais. ${ }^{1}$ Todavia, é importante salientar determinados princípios que, em nosso entendimento, nortearam a proliferação dessas regiões para além do fato da aglomeração urbana: em primeiro lugar, está a manutenção dos financiamentos públicos do governo federal exclusivamente voltado para essas regiões; em segundo lugar, a concentração geográfica de milhares de habitantes impõe ao poder público o atendimento de inúmeras demandas sociais (segurança, limpeza, transporte, abastecimento de água, luz etc.) que não podem ficar circunscrita aos limites políticos administrativos, além de se configurar como um fenômeno político eleitoral importante que é a concentração do eleitor; em terceiro, a possibilidade de uma atuação mais efetiva dos governadores nessas áreas urbanas importantes; por último, demonstra a capacidade de controle dos governadores sobre as Assembleias Estaduais, sendo estes os verdadeiros 'barões da federação', na feliz expressão de Abrúcio (2000). 


\section{A Região Metropolitana de Manaus}

Para compreender a elaboração política dessa nova região metropolitana é necessário situar a cidade de Manaus no contexto urbano-regional do Norte do país. Retomando conceitos básicos da rede urbana, podemos afirmar que a 'primazia' urbana no Norte do país sempre foi exercida pela cidade de Belém desde o período colonial. A hegemonia regional foi consolidada pela centralização de funções políticas e econômicas ao longo dos séculos 19 e 20, primeiro como capital da Província e depois como principal centro exportador de produtos da floresta onde o destaque foi a borracha.

A decadência da exportação desse produto reduziu a dinâmica da economia regional forçando o governo federal a adotar medidas compensatórias à falência de toda a cadeia extrativa. Da década de 1960 em diante o governo federal, de modo imperativo, executa todo um planejamento voltado para a integração da região à nação tomando por pressuposto fundamental o processo de colonização, densificando a região com populações vindas de diversos pontos do país para os projetos de assentamento.

Enquanto para o Estado do Pará o governo federal priorizou os assentamentos rurais ao longo das rodovias construídas, para o Amazonas houve a decisão de implantar uma "zona franca" na cidade de Manaus, uma área com regime de isenção tributária diversa com o objetivo de incentivar a vinda de indústrias e de comerciantes, para, a partir daí, irradiar o desenvolvimento regional. Tal modelo, de concepção perrouxiana, instituído em 1967, tinha prazo de validade de 30 anos, quando, acreditava-se, não seria mais necessário manter tais incentivos. O resultado, ao contrário da esperada irradiação, provocou uma concentração excessiva das atividades na cidade de Manaus, ao ponto de hoje a cidade ser responsável por aproximadamente $55 \%$ da população do Estado, contribuir com 95\% da arrecadação estadual e responder por 55\% da arrecadação de impostos federais da Região Norte gerados pela consolidação do Polo Industrial.

Resistindo a diversas crises - nacionais e internacionais -, pela própria vulnerabilidade do modelo, excessivamente vinculado ao exterior, a cidade de Manaus, a partir das duas últimas décadas do século 20, teve seu crescimento populacional acelerado, produzindo uma repartição na Região Norte, criando a Amazônia Oriental, liderada por Belém, e a Amazônia Ocidental, 
liderada por Manaus. Atraindo populações de diversos lugares do Brasil, mais um contingente maior da própria região e mais ainda do próprio Estado do Amazonas, Manaus ultrapassa a casa de um milhão e seiscentos mil de habitantes na estimativa do censo do IBGE em 2006, ganhando características de uma metrópole.

Com toda essa pujança econômica e de população, não deixou de ser objeto de intervenção e disputas acirradas no campo político. O governo da cidade termina sendo tão ou mais importante que o próprio governo estadual. 'Cidade primaz', exerce forte liderança na rede urbana estadual, possuindo uma fantástica capacidade de mais retirar do que dar em troca, drenando ainda, a partir da rede fluvial, excedentes produtivos de outros municípios. Os fluxos informacionais, porém, da cidade, por exemplo, são majoritariamente extrarregionais.

Historicamente os fluxos regionais foram comandados pelas bacias hidrográficas do Negro, do Amazonas, do Juruá, do Purus, do Madeira e de outros rios, tendo Manaus como o centro dessa extensíssima rede fluvial. Somente a partir da década de 1970 é que algumas rodovias começam a fazer a ligação com municípios do entorno da capital. Evidentemente que falar de entorno, proximidade, na Amazônia, merece algumas considerações. A baixa densidade demográfica sempre foi marca registrada da região amazônica; o predomínio do transporte fluvial instituiu uma temporalidade marcada por dias de viagens e não de horas; e a distância dos núcleos populacionais demonstra a rarefação de habitantes.

Já a ligação rodoviária atual de Manaus com o restante do Estado é a seguinte: ao Norte, está a cidade de Presidente Figueiredo, distante 106 quilômetros; a Leste, distante 65 quilômetros, está a cidade de Rio Preto da Eva, e seguindo pela mesma rodovia chega-se a Itacoatiara, distante 250 quilômetros da capital amazonense. Ao Sul da capital está a cidade de Iranduba, distante 25 quilômetros, por via rodoviária. Antes, porém, de acessar a rodovia é necessário realizar uma travessia de balsa pelo rio Negro, que dura em média 40 minutos, num percurso de 4 quilômetros, onde está prevista a construção de uma ponte. A partir daí atinge-se a cidade de Manacapuru, distante 75 quilômetros, e Novo Airão, distante 170 quilômetros. Enfim, atravessando o rio Amazonas por balsa, num percurso médio de uma hora, chega-se à rodovia BR-319, que possibilita atingir o município de Careiro-Castanho, distante 100 
quilômetros. Este, podemos dizer, é o entorno imediato da cidade de Manaus, acessível por via rodoviária ou rodofluvial, onde foi instituída a Região Metropolitana de Manaus.

Quando surgiu a discussão a propósito da criação da Região Metropolitana de Manaus, o projeto já estava elaborado na Assembleia Legislativa do Estado e nenhum dos prefeitos dos municípios envolvidos havia tomado conhecimento, nem mesmo o da capital, prefeito Serafim Corrêa. Lideranças do governo do Estado afirmaram que tal propósito surgiu a partir de uma solicitação de recursos federais, quando, em visita a Brasília, o governador Eduardo Braga obteve como resposta, no gabinete da Casa Civil do governo federal, que só havia recursos prioritários para as regiões metropolitanas e que Manaus não se enquadrava nesse critério. A alternativa, então, foi "fazer" esse território, operação que podemos denominar, metaforicamente, de "bragamandering", isto é, realizar recorte territorial institucionalizando e enquadrando dentro das normas - espaço normativo - da legislação estadual.

Assim nasceu a Região Metropolitana de Manaus composta pelos seguintes municípios: Rio Preto da Eva, Presidente Figueiredo, Iranduba, Novo Airão, Careiro da Várzea e Itacoatiara, aqueles que são limítrofes à capital (Mapa 1). Seu contingente populacional atinge aproximadamente 1,8 milhão de habitantes segundo a estimativa do Censo do IBGE em 2006, com uma surpreendente área de 97 mil quilômetros quadrados, extensão equivalente ao Estado de Santa Catarina, tendo, portanto, uma densidade demográfica de somente 20 habitantes por quilômetro quadrado. Em termos comparativos, é importante dizer que a Região Metropolitana de Belém possui 1,8 mil km² e $1.290 \mathrm{hab} . / \mathrm{km}^{2}$; a Região Metropolitana de Florianópolis possui 2,5 mil km² e $490 \mathrm{hab} . / \mathrm{km}^{2}$.

A principal insurgência não poderia ser outra senão do prefeito da capital, cuja preocupação era justamente o surgimento de uma nova correlação de forças a partir da criação desse novo espaço geopolítico, pois além de ter acesso aos recursos federais para a capital, compete também ao governo do Estado a nomeação dos membros que compõem o Conselho de Desenvolvimento Sustentável da Região Metropolitana de Manaus. 


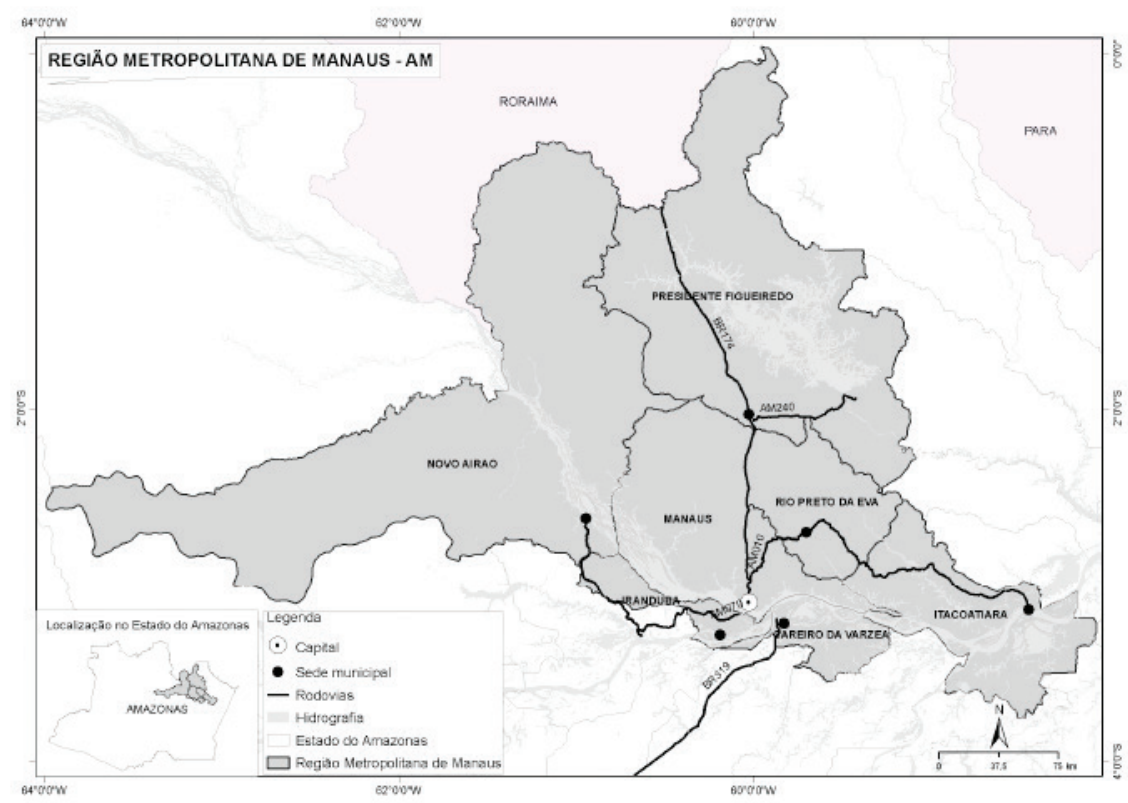

Figura 1 - Composição dos municípios da RMM.

Se como ferramenta essa regionalização demonstra de forma cristalina a possibilidade que o poder tem de manipular o espaço como lhe interessar, institucionalizando-o, como fato a Região Metropolitana de Manaus está longe de apresentar as características fundamentais como conurbação e intensidade de fluxos intermunicipais diversos, geradores de problemas comuns a dois ou mais municípios. Isso porque as sedes municipais da região estão muito dispersas. Itacoatiara, depois de Manaus, é o maior município dos demais e abriga em seu núcleo urbano uma população de 50 mil habitantes e está a 250 quilômetros da capital; Presidente Figueiredo conta com 12 mil habitantes e está localizado a 106 quilômetros de Manaus; Rio Preto da Eva com 7 mil habitantes apenas, está localizada a 65 quilômetros. Esses municípios são acessíveis por via rodoviária. Para ter acesso aos outros municípios da região metropolitana é necessário realizar a travessia do rio Negro, que dura 40 minutos de balsa (ferry-boat), como dissemos acima. A 23 quilômetros do porto atinge-se a cidade de Iranduba, com dez mil habitantes; seguindo na mesma rodovia, a 52 quilômetros está a cidade de Manacapuru com 50 mil 
habitantes, que pelo fato de não ser limítrofe a Manaus, não participa da região metropolitana. Novo Airão, ao contrário, mesmo com uma população de 5 mil habitantes e estando a 180 quilômetros de Manaus, participa do novo mapa.

Se retomarmos alguns pontos da lei complementar de 1973, que trata dos interesses metropolitanos referentes aos serviços comuns aos municípios, impõe-se interrogar quais seriam os serviços ou problemas comuns apresentados pela Região Metropolitana de Manaus. Em primeiro lugar, como não existe conurbação - essência da região metropolitana -, não haveria serviços ou problemas comuns. Quando duas cidades, no processo de expansão urbana, aproximam ou unem suas malhas, ocorre a necessidade de os executivos municipais definirem ações comuns tais como a organização do abastecimento de água e rede de esgoto, bem como a própria limpeza pública; o transporte urbano também deve estruturar sua malha viária com vista a atender os municípios envolvidos. Ainda o próprio uso dos recursos hídricos e controle da poluição deles e a regulamentação do uso do solo.

A distância entre os núcleos urbanos da Região Metropolitana de Manaus exime qualquer município dessas preocupações, uma vez que não há compartilhamento de problemas gerados porque não há conurbação. Os fluxos existentes entre os municípios não permitem aquele tipo de migração diária que ocorre em outras regiões metropolitanas, quando, por exemplo, milhares de trabalhadores saem de suas casas num município para trabalhar em outro, gerando aquilo que se convencionou chamar de cidades-dormitórios, exigindo, inclusive, grandes programas habitacionais. É comum sair de Osasco e trabalhar em São Paulo; de Olinda e trabalhar no Recife; sair de Vila Velha e trabalhar em Vitória; de Duque de Caxias e ir ao Rio de Janeiro etc. A densidade da malha viária, dos fluxos de ônibus ou trens, terminais, conexões, permite tal mobilidade. Regra geral, a intensidade do uso do solo urbano não deixa lugar para atividades rurais, empurrada para a periferia da região metropolitana. Na Região Metropolitana de Manaus, dezenas de quilômetros de floresta separam os núcleos urbanos.

\section{Considerações finais}

O pensamento geográfico sobre o espaço urbano elegeu como instância prioritária de análise, nas três últimas décadas, o viés econômico e com isso 
explicou diversos processos inerentes à "produção do espaço urbano" como a valorização e uso do solo; distribuição das atividades no interior da cidade; distribuição dos equipamentos públicos diferenciada por bairros centrais e periféricos; a especulação imobiliária etc. Da política urbana destacou-se as questões associadas aos movimentos sociais urbanos e suas reivindicações ao direito à cidade: habitação, transporte, água e outros requisitos.

O que tentamos expor foi como o espaço urbano também pode ser produzido a partir de recortes territoriais realizados pelo poder do Estado com a finalidade básica de controlar as ações políticas nesse território, tomando como referência a criação de uma entidade territorial urbano-regional: a região metropolitana, de caráter eminentemente administrativa e não política, na medida em que sua gestão não se dá por representantes da população, mas por um conselho delegado pelos governos estaduais.

Mostrou-se que a criação da Região Metropolitana de Manaus distorce todo o princípio que norteia o estabelecimento dessas áreas, porém ratificou-se que o poder instituído utiliza o espaço para realizar a regionalização que lhe interessa, sendo, por isso mesmo, instrumento, ferramenta fundamental das relações de poder entre os agentes sociais.

Embora a cidade de Manaus já contabilize uma população superior a 1,5 milhão de habitantes, fazendo dela uma das dez maiores cidades do Brasil, não pode rigorosamente constituir uma região metropolitana, pois, como foi exposto, os fluxos intermunicipais, em razão das distâncias - e isso é uma questão mesma de fricção -, não possuem densidades que caracterizam, que marcam as regiões metropolitanas no Brasil.

\section{Notas}

${ }^{1}$ As regiões metropolitanas criadas em 1973 são as seguintes: São Paulo, Rio de Janeiro, Belo Horizonte, Salvador, Recife, Fortaleza, Curitiba, Belém e Porto Alegre. As RMS criadas após 1988 são: Maceió, Macapá, Vitória, Goiânia, São Luís, Vale do Aço, João Pessoa, Londrina, Maringá, Natal, Aracaju, Florianópolis, Vale do Itajaí, Norte/Nordeste catarinense, foz do rio Itajaí, Carbonífera, Tubarão, Baixada Santista e Campinas. 


\section{Referências}

ABRÚCIO, Fernando. Os Barões da Federação. São Paulo: Hucitec, 2002.

BRITTO, Luiz Navarro. Política e Espaço Regional. São Paulo: Nobel, 1986.

CLAVAL, Paul. Espaço e Poder. Rio de Janeiro: Zahar Editores, 1979.

CORRÊA, Roberto L. Região e Organização Espacial. São Paulo: Ática, 1990.

HARVEY, David. Justiça Social e Cidade. São Paulo: Hucitec, 1982.

LACOSTE, Yves. A Geografia. História da Filosofia. Vol. 7. Rio de Janeiro: Zahar, 1974.

LEFEBVRE, Henry. Espacio y Política. Barcelona: Ediciones Península, 1976.

OLIVEIRA, Francisco. Elegia para uma re(li)gão. São Paulo: Paz e Terra, 1977.

RAFFESTIN, Claude. Por Uma Geografia do Poder. São Paulo: Ed. Ática, 1993.

RIBEIRO, Ana C. Regionalização: Fato e Ferramenta. In: LIMONAD, Ester et. ali. (Orgs.). Brasil, Século XXI: Por uma nova regionalização? São Paulo: Ed. Max Limonad, 2004.

ROLNIK, R. e SOMECK, N. Governar as metrópoles: dilemas da recentralização. In: GONÇALVES, Maria Flora; GALVÃO, A. C. (Orgs.). Regiões e Cidades. São Paulo: Ed. Unesp, 2003.

SANTOS, Milton. A Urbanização Brasileira. São Paulo: Hucitec, 1994. e SILVEIRA, Laura. O Brasil: Território e Sociedade. Rio de Janeiro: Record, 2001.

SOUZA, Celina. Regiões metropolitanas: condicionantes do regime político. Lua Nova, n. 5, São Paulo, 2003. 